\title{
Facilitating project management through effective quality management: the need for implementing ISO 9000 in construction
}

\author{
N.D. Gunawardena
}

\begin{abstract}
This paper describes the relationship between project management and quality management. It identifies the similarity between the recognised project quality management processes and the ISO 9001 quality management system; then it illustrates how ISO 9001 quality requirements could be applied to construction project management. The paper also presents the results of a survey carried out to identify quality management practices adopted by local construction companies, using ISO 9001 standard as a yardstick. According to the survey, the companies had some shortcomings with respect to quality management during the construction stage. The results indicate that the lack of proper quality management could, in turn, affect the project management adversely; this point is supported by the Project Management Process Maturity Model, which is a quality improvement model that uses five levels to determine the relative maturity of any organisation and its ability to achieve cost and schedule objectives of a project. Finally, the paper suggests that the quality managements systems based on ISO 9000 could be very effective in facilitating the project management efforts in the construction industry.
\end{abstract}

\section{Introduction}

A project can be defined as a complex, non-routine, one-time effort limited by time, budget, resources and performance specifications (Gray and Larson, 2000). Project Management is the application of knowledge, skills, tools and techniques to project activities in order to meet or exceed stakeholder need and expectations from a project (PMI, 1996). Accordingly, those who rnanage projects must not only strive to meet specific scope, time, and performance goals of the project; they must also facilitate the entire process to meet the needs and expectations of the people involved in or affected by project activities.

Construction industry deals with products that are expensive, complex, immovable and long-lived. They are unique in nature and seldom offer scope for repetition. The project approach has long being the style of doing business in the construction industry. As Peter Morris (1994) quite correctly points out:

\begin{abstract}
'Managing Projects is one of the oldest and most respected accomplishments of mankind. We stand in awe of the achievements of the builders of pyramids, the architects of ancient cities, the masons and craftsmen of great cathedrals and mosques; of the might and labour behind the Great Wall of China, and other wonders of the world.'
\end{abstract}

Construction projects are usually carried out in the form of contracts. The essence of a construction contract is that two parties together make a deal whereby, one party, called the client, promises to provide some consideration or payment in exchange for the services offered by the other party, the contractor. Therefore, both parties must have mutual understanding as to what services are to be provided by the contractor in return for the agreed consideration; this usually is ensured by a set of documents such as drawings and specifications that define the scope and the performance aspects of the product. Clients may need to employ an architect or a consulting engineer, or perhaps both, to carry out the design work and to provide the above documents, and supervising the work done by the contractor during the construction stage; this is often the case when the clients do not have the knowledge and skills required to undertake such activities themselves.

A construction project is regarded as successful if the product is completed within schedule, budget and quality standards, and achieves a high level of client satisfaction; but this may also depend to certain extent on the type of contract or the method of procurement as well (Naoum, 1994). The type of contract, mentioned above, is called the 'Traditional Contract', and there are other types of contract such as the Management Contract, the Construction Management Contract and the Design and Build Contract (Ashford, 1989). However, the discussion presented in this paper is limited to the traditional contracts as this is the most predominantly used type in construction work in Sri Lanka.

\section{Quality Management in Construction}

There are many different definitions of quality. These definitions vary from "Conformance to requirements" (Crosby, 1979) to "the totality of features and characterise of a product that bear on its ability to satisfy stated or implied needs "(ISO 8402, 1994). 
Quality in construction is not only meeting product quality requirements, but also is directly related to the time and cost associated with the works; poor quality always results in unnecessary time extensions and/or extra costs in rectifying deficiencies. Therefore the approach used for managing quality determines to a great extent the success of the project.

The approaches to managing quality can take various forms such as quality control, quality assurance and total quality management (TQM).

\section{Quality Control:}

Quality control includes 'the operational techniques and activities that are used to fulfil requirement for quality' (ISO 8402, 1994). This is considered as the simplest approach to managing quality and traditionally, and it has been the main approach to manage quality in construction. It is primarily concerned with detection of defects through inspection and testing, and sometimes using statistical techniques (Olomolaiye, et al., 1998).

The problem with quality control is that it does not build quality into the product; as mentioned above, the quality of the finished product is, instead, checked by way of inspection and testing. Therefore, it is frequently argued that many construction defects are covered up during subsequent activities and consequently the finished works cannot be assessed by final inspection (Chung, 1999). Even if defects are identified in finished works they are very difficult, if not impossible, to replace. As a result, the client is sometimes left with a patched up product with poor quality.

\section{Quality Assurance:}

The situation is much better in quality assurance, which includes 'all those planned and systematic actions necessary to provide adequate confidence that product or service will satisfy given requirements for quality' (ISO 8402, 1994) and has a broader scope than that of quality control. It is the implementation of processes, which aim to ensure that concern for quality is designed and built into prodwcts or services. It covers the entire life cycle of a construction project in a planned and systematic way; the primary objective is to provide the necessary confidence to the client that all concerned with project are carrying out their activities effectively to meet his requirements. This approach had been first applied to manufacturing processes at the beginning of modern industrialisation (Devos et al, 1996), though it was only in 1987, an international standard for quality assurance systems, referred to as ISO 9001, was published. ISO 9001 (1987) introduced a framework or formal arrangements for quality assurance, and is universally adopted by organisations in managing quality (Dick, 2000).
Total Quality Management (TQM):

The approach used in TQM is based on the analytical evaluation of work processes, the development of a quality culture, and the empowerment of employees for the purpose of continuous improvement of the product or service (Hellard, 1993). Unlike quality assurance, TQM aims to address all aspects of a business including people, methodology and technology; it emphasises on customer satisfaction as well as continuous improvement (Jawahar-Nesan and Price, 1997). TQM has become more popular in the manufacturing industry than in the construction industry (Arditi and Gunaydin, 1999). It is known that many construction companies that have addressed the issue of quality are quality assurance-oriented and only a relatively few have implemented TQM for this purpose (Sommerville and Robertson, 2000).

New Quality Management Approach of ISO 9001:

The International Organisation for Standardisation revised the ISO 9001 standard twice since its introduction, in 1994 and 2000, and it is now called 'Quality Management System Requirements' rather than 'Quality Systems - Model for Quality Assurance'.

The quality management approach described in the latest ISO 9000 standard (ISO 9001, 2000) could be illustrated using the methodology known as "Plan-DoCheck-Act' (PDCA)'. The PDCA cycle is shown in Figure 1.

Plan

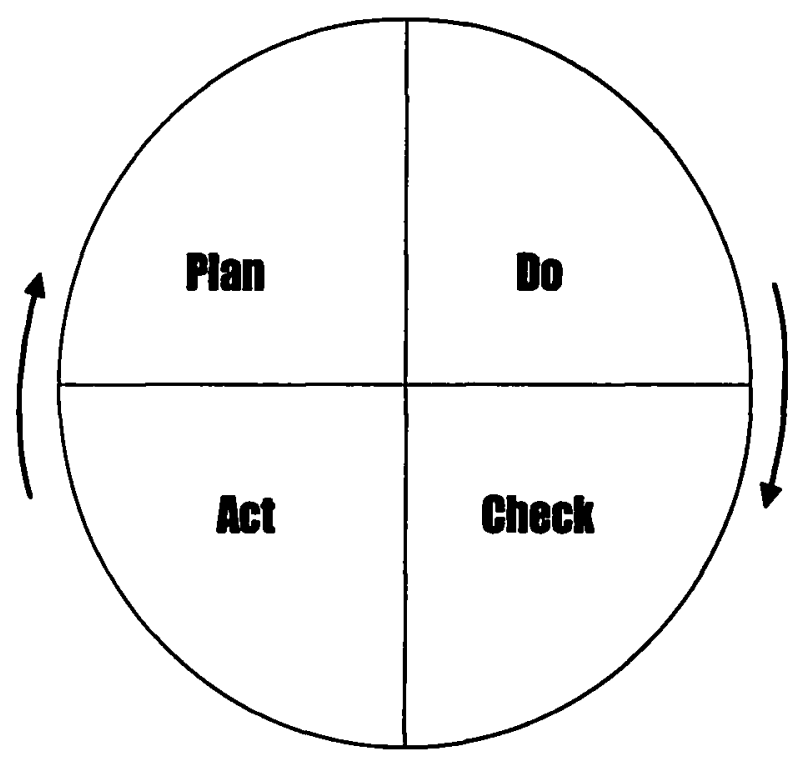

\section{Figure 1: PDCA Cycle}

The above activities can be defined as follows (ISO 9001, 2000):

- Plan:establish objectives and processes necessary to deliver results in accordance with customer requirements and the organisation's policies

- Do: implement the processes 
- $\quad$ Check: monitor and measure processes and product against policies, objectives and requirements for the product and report the results

- Act: Take actions to continually improve process performance

This new concept of quality management covers a wider area than Quality Control. In fact, quality control could be considered as part of quality assurance; it is primarily concerned with the 'Do-and 'Check' activities of the PDCA cycle.

\section{Project Quality Management based on ISO 9001}

The main purpose of project quality management is to ensure that the project will meet or exceed stakeholder needs and expectations. In projects, quality is directly related to and must be viewed on an equal level with the customer requirements in terms of project scope, time and cost; which are also know as triple constraints of a project. In a construction project these are expected to be clearly defined in the contract documents.

Project quality management involves three main processes (PM1, 1996):

- Quality Planning: identifying which quality standards are relevant to the project and determining how to satisfy them

- Quality Assurance: evaluating overall project performance on a regular basis to provide confidence that the project will satisfy the relevant quality standards

- Quality Control: monitoring specific project results to determine if they comply with relevant quality standards and identifying ways to eliminate causes of unsatisfactory performance

It could be seen that the above processes are in line with the PDCA cycle presented in the ISO 9001: 2000 standard; accordingly, Quality Planning (Plan), Quality Assurance (Do \& Act), and Quality Control (Check) all work in a cycle to achieve project quality. In fact, the project quality management approach described above is intended to be compatible with that of the International Organisation for Standardisation as detailed in the ISO 9000 and ISO 10000 series of standards and guidelines (PMI, 1996). Therefore, in the following three sections, the above approached is described briefly, in order to illustrate how ISO 9001 quality requirements could be applied to construction project management.

\section{Project Quality Planning}

As mentioned earlier quality planning involves identifying which standards are relevant to the project and determining how to satisfy them. It is one of the key facilitating processes during overall project planning. It must be performed in parallel with other project planning processes such as cost and schedule planning; this is so because the desired quality may require cost or schedule adjustments.

In traditional contracts, the Consultant identifies the relevant standards applicable to the works, even before the contractor is selected. Therefore, part of the quality planning obviously, becomes the responsibility of the Consultant.

According to ISO 9001 (2000), quality planning must first develop quality objectives, including those needed to meet requirements for the product (of the project). The standard also requires that these quality objectives are measurable and consistent with the quality policy of the organisation. Major difficulty in this regard is that a project involves multiple performing organisations and they may lack formal quality policies. The Project Management Institute (PMI, 1996) recommends that in such case a quality policy be developed for the project. The project quality objectives must described what is to be accomplished be expressed in terms of time, cost and product characteristics, and, where possible, be measurable (ISO 10006, 1997).

The output from quality planning exercise is the Project Quality Plan. It is the project management team's responsibility to develop a quality plan for the project. Once the contract has been awarded, the project team would mainly consist of the Contractor's employees; however, as the Consultant would play a major role in supervising the works, he should become a member of the project team as well.

The quality plan should describe how the project management team would achieve quality objectives of the project. In ISO 9000 terminology, it should describe the project quality system: 'the organisational structure, responsibilities, procedures, processes and resources needed to implement quality management' (ISO 9001, 1994). The main purpose of such a system is to direct and control project management team with regards to quality. In planning the project quality system the project management team, should (ISO 9001,2000 ).

(a) Identify the processes needed for the quality system and their application throughout the project

(b) Determine the sequence and interaction of these processes

(c) Determine criteria and methods needed to ensure that both the operation and control of these processes are effective 
(d) Ensure that availability of resources and information necessary to support the operation and monitoring of these processes

(e) Monitor, measure and analyse these processes, and

(f) Implement actions necessary to achieve planned results and continual improvement of these processes

As it would be seen from the description given above the quality plan is a document setting out the specific quality activities and resources pertaining to a particular contract or project. The contents of the quality plan are drawn from the contractors quality system (if the company has such a system) and the contract documents.

At present in Sri Lanka it is difficult to expect a significant contribution from a contractor's quality management system; this is because only a hand full of contractors have obtained ISO certification (De Silva and Goonatillake, 2000). But the good thing is that, it is still possible for a non - ISO certified contractor.to develop and adopt a project quality plan using the ISO 9001 standards as the basis. The quality plan so developed with the guidance of ISO standards could be considered as the 'quality manual' tailor-made for the project.

A typical quality plan would contain (Chung, 1999):

(a) Brief description of project and Site Layout Plan

(b) Project quality objectives

(c) Project organisation chart including responsibilities and authorities of project staff

(d) List of contract documents and drawings

(e) Construction programme and subprogrammes

(i) Schedules of subcontractor nomination, material and equipment procurement, based on the construction programme

(g) Lists of materials and plant used for the works and their verification requirements

(h) List of inspection and test plans

(i) List of quality procedures and work instructions applicable to the project 1

(j) List of quality records to be kept, including pertinent quality records' from sub contractors Frequency of quality audits (or audit programme)

(I) Frequency of updating the quality plan

The quality plan should be updated through periodic reviews. These reviews should, therefore, be identified, planned for and scheduled in the quality plan itself. The purpose of such reviews is to ensure the continuing suitability, adequacy, and effectiveness of the quality system (ISO 9001, 2000); at project level, the quality system is documented in the quality plan (ISO 10006, 1997).

\section{Project Quality Assurance}

It is one thing to develop a plan for managing quality on a project; it is another to ensure quality is in fact achieved. In a project quality assurance is all the planned and systematic activities implemented to provide confidence that the project will satisfy the relevant quality standards (PMI, 1996). It basically is implementation of the quality plan throughout the project. Another goal of quality assurance is continual quality improvement.

Important areas where quality assurance is a applicable during the construction stage are listed below (Lam et al., 1994):

(a) control of contract documents

(b) purchasing materials services and plant used for the works

(c) inspection and testing of works

(a) quality procedures and work instructions applicable to the project

(b) quality records to be kept, including pertinent quality records from sub contractors

(c) quality audits

\section{Contract Documents:}

The Conditions of Contract (ICTAD, 2002) clearly specifies contract documents (in order of priority) as:

1. Agreement

2. Letter of Acceptance

3. Memorandum of Understanding (if any)

4. Contractor's Bid

5. Contract Data

6. Conditions of Contract

7. Specifications

8. Drawings

9. Bill of Quantities

10. Any other document listed in the contract data as forming part of the Contract

Except for the Drawings, and those listed under the last item above, all the other documents are usually unique and do not change during the project duration. Particularly for documents and drawings issued by the Consultant to the contractor, the ISO 9001 requirement could be applied to assure quality.

Accordingly the Contractor shall:

- Ensure that changes and the current revision status of documents are identified

- Ensure that relevant versions of applicable documents are available at points of use

- Ensure that the distribution of these documents is controlled

- Prevent the unintended use of obsolete documents, and to apply suitable identification to them if they are retained for any purpose. 
In addition, ISO 9001 requirements that are applicable to Consultant are as follows:

- To approve documents for adequacy prior to use

- To review and update as necessary and re-approve documents

- To ensure that documents remain legible and readily identifiable

For those documents such as quality assurance procedures and work instructions that are developed by the Contractor himself, all of the above mentioned ISO requirements should be applied.

Purchasing materials services and plant used for the works and these verification requirements:

In this regard the Contractor shall ensure that (ISO9001, 2000):

- Purchased products (materials, services or plant) conform to specified purchase requirements

- Control is applied to the supplier and the purchased product; the type and extent shall depend on the effect of the purchased product on the works.

- Suppliers are evaluated and selected based on their ability to supply product in accordance with the requirements.

- Criteria for selection, evaluation, and reevaluation of suppliers are established.

- Purchasing information accurately describe the product to be purchasing.

- The inspection or other activities necessary are established and implemented for ensuring that purchased product satisfies purchase requirements.

Inspection and Test plans:

It is often realized by construction managers that specifications (Ashford, 1989). Therefore, it is always convenient to assemble all inspection and testing requirements relevant to a particular operation or process in the sequence in which they should be performed. Such documents are called inspection and test plans (ITP).

The following are some processes for which ITPs should be prepared (Chung, 1999):

- Foundation work

- Concrete work

- Pre-cast work

- Erection of steel work

- Waterproofing

- Plumbing and drainage work

- Instaliation of cladding, façade etc

- Installation of fire-fighting equipment

- Installation of building services

- Special processes such as woodwork for acoustic effects

Quality procedures and work Instructions Applicable to the project:
The schedule (construction program) developed for a project only gives broadly the name and the date of commencement of the work activities. It does not give a detailed description of the work: what exactly is to be done; who should carryout the work; and how should it be carried out.

If quality is to be assured in a project, the quality system must consist of procedures and work instructions that explain and detail the processes as above. They indicate the methods used and criteria to be satisfied (Nee, 1996)

The project quality plan, therefore, should make reference to the respective documents (procedures, work instructions and checklists) by number and title. The project team should develop these documents including that are specific to the particular project.

\section{Quality Records to be kept:}

As the underlying philosophy of quality management is to provide documentary evidence that the specified quality has been achieved (CIOB, 1988), the quality records play a vital role in construction projects. Typical records include:

- Material receipt and dispatch forms

- Manufactures certificates

- Material test reports

- As-built drawings

- Minutes of site meetings

- Instructions issued by the Consultant.

The quality plan should show a list of all quality records to be established and maintained. ISO9001 (2000) guidance with respect to the other types of records to be kept is also very useful; it identifies the following records as important:

- Details of personnel working on the project

- Changes of project requirements including design changes

- Evaluation of suppliers

- Information necessary for traceability

- Lost, damaged or unsuitable items supplied by the client

- Calibration records of measuring devices

- Remedial, corrective and preventive action.

- Audits reports

- Lessons learned

Quality Audits:

A quality audit is a formal review of quality management activities. The purpose of a quality audit is to identify lessons learned that can improve the performance of the project or other projects handled by the company (PMI, 1996). Particularly, internal quality auditing checks the adherence to the quality plan. These audits could be scheduled based on the anticipated progress of the project; if not, at least, the frequency could be stated in the quality plan. 


\section{Project Quality Control}

In projects, quality control involves specific project results to determine if they comply with relevant quality standards and identifying ways to eliminate the root causes of any undesirable results. The tools and techniques available for quality control include (PMI, 1996):

- Inspection

- Control charts

- Pareto diagrams

- Statistical sampling

- Flowcharting

- Trend analysis

Remedial action such as rework on defective or nonconforming items is one of the outputs of quality control activities in a project; the others include process improvements such as corrective or preventive action as a result of quality control measurements.

\section{The Need for Implementing ISO 9000 in Construction}

A research study was carried out in 2000 with the objective of identifying quality management practices adopted by contractors during the construction stage (Kandamby, 2000). As part of the study questionnaire survey was administered to 36 contractors randomly selected using a list of building construction sites. Except for two contractors, others were all contractors registered with the Institute for Construction and Training (ICTAD). The survey was carried out using the ISO 9001 (1994) standard as the basis for evaluating the quality practices of the contractors.

Only the companies with ISO 9000 certification had quality plans developed for their projects. Using a questionnaire, some quality problems during construction stage were identified during the survey; they are described briefly under the important areas listed in the section on quality assurance:

\section{Control of contract documents:}

Only the contractors, who had ISO certification, positively responded to the practices regarding document control such as review and approval of both the original documents and subsequent changes made to them. The main finding, with respect to document control, was the non-availability of construction specifications at most of the sites surveyed; only $38 \%$ of the sites surveyed had these on sites. Non-availability of construction specifications at site or the lack of proper use of these in executing work could be seen as a major barrier in achieving quality during the construction stage.

Purchasing materials senvices and plant used for the works:

Evaluation of suppliers, prior to purchasing of materials, could hardly be seen among contractors; only $52.8 \%$ of the contractors had some form of evaluation and selection procedure. Only $5.6 \%$ of the contractors appeared to consider all the important factors in the evaluation: evidence of quality of materials, previous performance (if any) and inspection of materials and quality assurance measures at suppliers' premises. However, the use of verbal means in ordering materials as oppose to written purchase orders could be seen as the weakest area as far as purchasing is concerned; this situation - the lack of purchase documents to specify the required quality of materials in sufficient details - could seriously affect the quality of the works.

In the case of subcontractors, most of the contractors $(69.7 \%)$ were using some method of evaluation. However, their evaluation is mainly based on the previous performance of the subcontractors $(60.9 \%)$; only very few of them used evidence of quality of work (perhaps through letters of recommendation) and inspection of the work and quality assurance measures at subcontractors' premises.

\section{Inspection and testing of works:}

Inspection and testing activities carried out by most of the contractors are not adequate. More than $90 \%$ of the contractors relied heavily on visual inspection without a checklist and most of them did not stick to specifications for testing of materials and works. Only $27.8 \%$ of the contractors surveyed were undertaking in-process testing; this appeared to be carried out mainly for controlling the quality of reinforced concrete work. However, visual inspection of the works was reported as the principal verification activity of all contractors during the in-process stage. According to the contractors, there were no separate testing as such carried out on completion of the works and verification activities were limited to final inspection of the structure for visible defects.

\section{Quality procedures and work instructions applicable} to the project:

The questionnaire considered all aspects of the documents, including the use of proper procedures for review and approval of and making changes to the documents and the availability of them at site. The responses were not very encouraging: only one contractor, an ISO certified company, satisfied all these aspects for both quality system and project specific documents. Other contractors did not have quality system documents as none them had any formal quality system in place. According to the survey, only $16.7 \%$ of the contractors agreed that they were using documented procedures defining the manner of execution of work. Many contractors appeared to depend too much on the experience of workmen in achieving quality of workmanship. This is not a very desirable situation, particularly, when there is a lack of qualified supervisory staff at building sites. 


\section{Quality records:}

It was found during the survey, that only the contractors with ISO certification maintained quality records on both materials and workmanship with respect to all aspects of the works executed in order to verify that they have complied with construction specifications and all other requirements of quality. Only about $14 \%$ of the contractors maintained inspection and test records with respect to materials used for some materials; a little over $11 \%$ of them had records of concrete work.

\section{Quality audits:}

As expected only the ISO certified company carried out quality audits to verify effective and efficient implementation of the quality management system.

None of the contractors reported that they used quality control techniques such as control charts, Pareto diagrams, statistical sampling, and trend analysis. Further, 'Corrective Action' - identifying the root causes of nonconformities and eliminating them - was found to be practiced only by ISO certified contractors; 'Preventive Action' to eliminate potential nonconformities was almost non-existent.

It was also revealed that only about $20 \%$ of the contractors surveyed satisfied, at least, one third of the sub-elements (quality requirements of the standard) presented in the questionnaire. The most important point, however, is that the ISO 9000 certified contractors among the sample did not have any of the problems highlighted above.

Finally, based on the results of this study, it could be concluded that the quality management practices in the industry during the construction stage are not very effective, and their contribution to project management is at low level. This could also lead to cost overruns and delays as well.

\section{The Concept of Project Management (PM) Process Maturity: \\ The Project Management Process Maturity Model developed by Micro-Frame Technologies, Inc. and Project Management Technologies, Inc. could also be used to support the above conclusion. The model is useful in pinpointing an organisation's current project management maturity level. The primary purpose of the model is for use as a reference point or yardstick for an organisation applying project management processes (Ibbs and Kwak, 1997). The model is illustrated in Figure 2.}

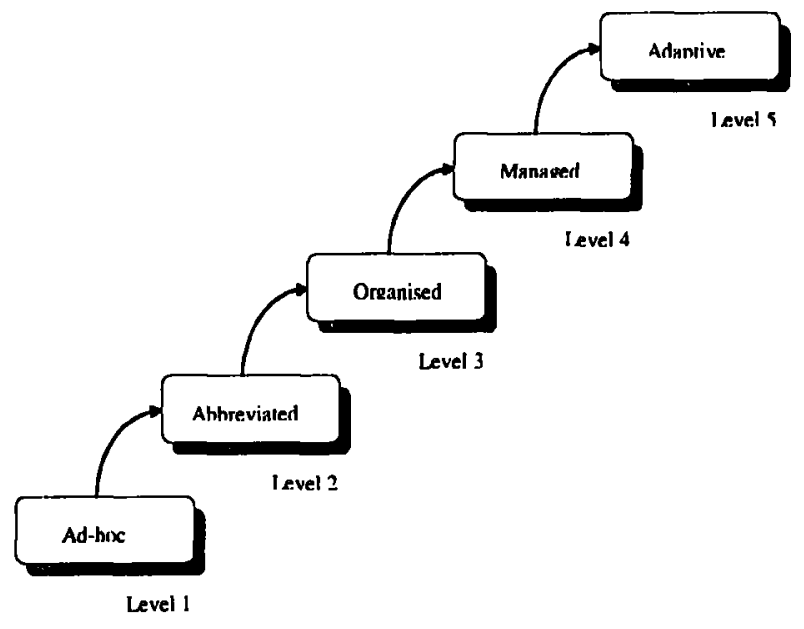

Figure 2: Project Management Process Maturity Model 2

The model has the following basic levels:

1. Ad-hoc: The project management process is described as disorganised and occasionally even chaotic. The organisation has not defined systems and processes, project success depends on individual effort. There are chronic cost and schedule problems.

2. Abbreviated: There are some project management processes and systems in place to track cost, schedule and scope. Project success is largely unpredictable and cost and schedule problems are common.

3. Organised: There are standardised, documented project management processes and systems that are integrated into the rest of the organisation. Project success is more predictable; cost and schedule performance is improved.

4. Managed: Management collects and uses detailed measures of the effectiveness of the project management. Project success is more uniform; cost and schedule performance conforms to plan.

5. Adaptive: Feedback from the project management process and from piloting innovative ideas and technologies enables continuous improvement. Project success is the norm; cost and schedule performance is continuously improving.

Ibbs and Kwak (2000) have found that organisations in the construction industry, generally, have a higher maturity level than those in the Information Technology (IT) and software industries. However, according to the description of the maturity levels, most of the construction companies surveyed appeared to adopt project management processes (with respect to project quality) at Level 1 and Level 2 of the model. As the model suggests, at those levels of maturity, delays and cost overruns are quite common. Construction 
companies with ISO 9000 certification fall into the 'Organised' category at Level 3 of the maturity model; at this stage, it is expected that project success would be more predictable and cost and schedule performance could be improved. Further analysis of the construction companies showed that large contractors (M1 and M2) appear to have better quality management practices than smaller contractors. This again suggests that as the companies climb up the ICTAD registration ladder, they, also seem to mature in project management processes; in these companies there are some processes and systems in place to assure project quality management. Therefore, it is reasonable to say that ISO 9000 could improve the project management processes in construction companies; and large companies would be in a better position to implement it as their existing quality management practices show higher project management process maturity levels compared to small companies.

\section{Conclusions}

The main purpose of project quality management is to ensure that the project will satisfy the needs for which it is undertaken; whereas project management involves meeting or exceeding stakeholder needs and expectations. Therefore, in projects, quality management and project management are directly related and inseparable. The widely used project quality management processes - Quality Planning, Quality Assurance, and Quality Control - are found to be compatible with quality management approach of the Intemational Organisation for Standardisation as detailed in the ISO 9000 and ISO 10000 series of standards and guidelines.

The survey carried out among construction companies, using the ISO 9001 quality requirements as a yardstick, reveals some shortcoming in their quality management practices during the construction stage. Quality management processes in most of the construction companies surveyed were not very effective, and their contribution to overall project management could not be considered satisfactory. This could also lead to cost overruns and delays as well. Most of the construction companies surveyed appeared to adopt project management processes (with respect to project quality) in the lower part of the PM Process Maturity Model. As the model suggests, at those levels of maturity, delays and cost overruns are quite common. Construction companies with ISO 9000 certification fall into the 'Organised' category at higher level of the maturity model; at this stage, it is expected that project success would be more predictable and cost and schedule performance could be improved.

As the research study presented in this paper indicates, better project quality management is necessary for project success; and implementation of quality management systems based on 1509000 in construction organisations is an effective way of achieving this. However, there are only few construction companies with ISO Certification in Sri Lanka (De Silva and Goonatillake, 2002), which indicates that the local contractors have not yet realised the importance of such a formal quality management system. Therefore, steps should be taken to motivate them to implement the ISO 9000 system in their companies. One way to do this would be to offer financial assistance for them to cover, at least, part of the implementation costs. For example, United Kingdom had already implemented such a programme successfully (Giles, 1997). According to the experiences of other countries, 'client pressure or requirement' is also found to be a major motivating factor for construction companies to implement ISO $\mathbf{9 0 0 0}$ standards. The Government being the largest client in the construction industry can insist on quality assurance systems for its major projects as the initial step. The Institute for Construction Training and Development (ICTAD) also has a major role to play in this regard; as the regulatory body in the construction industry, ICTAD can make a fundamental shift in the basic approach to quality management in construction. This would perhaps require the inclusion of quality assurance clauses in the contract documents ' and changes in the tender procedures as well. It is also recommended to undertake a research study with ISO Certified construction companies in Sri Lanka to identify costs and benefits of certification, and the difficulties in implementing ISO 9000 in the construction industry. The lessons learned from these companies would be very useful to the contractors who are planning to implement the standards in their organisations.

Finally, this paper is not intended to prove that ISO Certification should be mandatory for achieving quality of construction works; instead, it is aimed at describing how quality could be effectively managed at project level using a framework based on ISO 9000 standards in order to facilitate the project management processes.

\section{References}

Arditl, D. and Gunaydin, H. M. (1999) Perceptions of process quality in building projects. Journal of Management in Engineering, 15(2), 43-53.

Ashford, J.L. (1989) The Management of Quality in Construction, E. \& FN Spon, London.

Chung, H.W. (1999). Understanding Quality Assurance in construction - A practical guide to ISO 9000 for contractors, E \& F N Spon, London.

CIOB (1988). Quality Assurance in the Building Process, The Charted Institute of Building ,U.K.

Crosby, P. (1979) quality is Free, McGraw-Hill, New York.

De Silva G.M.S. and Goonatillake L. (2001) ISO 9000 Certification: Impact on the Output and 
Activities of a Sample of Sri Lankan Companies , $3^{\text {rd }}$ National Convention on Quality: Competitiveness through Quality Management Colombo, 21-22-November 2001, Sri Lanka, Association for Quality.

Devos, J.F. Guerrero-Cusumano, J.L. and Selven, W.J. (1996) ISO 9000 in the Low Countries reaching for new height? Business Process Reengineering and Management Journal, 2(1), 26 $-47$

Dick, G.P.M. (2000), ISO 9000 Certification benefits, reality or myth? The TQM Magazine, 12(6), $365-371$

FIDIC (1999). Conditions of Contract for Construction, International Federation of Consulting Engineers.

Giles, R. (1997) ISO 9000 perspective for the construction industry in the UK Training for Quality, 5(4), 178-181.

Gray, C.F. and Larson, E.W. (2000) Project Management - The Managerial Process, Irwin McGraw-Hill, New York

Hellard, R.B. (1993) Total Quality in Construction Projects-achieving profitability with customer satisfaction, Thomas Telford, London bbs, C.W. and Kwak, Y.H. (1997) Measuring Project Management's Return on Investment. PM Network, 36 - 38

Ibbs, C.W. and Kwak, Y.H. (2000) Assessing Project Management Maturity. Project Management Journal, March

ICTAD (1989) Conditions of Contract for works of Building \& Civil Engineering - Sri Lanka, Institute for Construction Training and Development, Sri Lanka

ICTAD (2002) Conditions of Contract, Institute for construction Training and Development, Sri Lanka.

ISO 8402 (1994) Quality - Vocabulary, International Organisation for Standardization. Stockholm.

ISO 9001 (1987) Quality systems - Model for Quality Assurance in Production, Installation and Servicing, International Organisation for Standardization, Stockholm

ISO 9001 (1994) Quality systems - Model for Quality Assurance in Production, Installation and Servicing, International Organisation for Standardization, Stockholm
ISO 9001 (2000) Quality Management Systems Requirements, International Organisation for Standardization, Stockholm.

ISO 10006 (1997) Quality Management - Guidelines to Quality in Project Management, International organisation for standardization Stockholm

Jawahar-Nesan, L. and Price, A.D.F. (1997) Formulation of best practices for owner's representatives. Journal of Management in Engineering, 13(1), 44-51.

Kandamby, G.W.T.C. (2000) Quality Management Practices of Building Contractors at Site Level, M.Sc Thesis, University of Moratuwa

Lam, S.W., Low, C.M. and Teng, W.A. (1994) ISO 9000 in Construction, McGraw-Hill Book Co, Singapore.

Morris, P.W.G. (1994) The Management of Projects, Thomas Telford services Ltd., London

Naoum, S.G. (1994) Critical Analysis of Time and Cost of Management and Traditional Contracts, Journal Construction Engineering and Management, 120(4), 687-705.

Nee, P.A. (1996) /SO 9000 in Construction, John Wiley \& Sons, Inc. New York

Olomolaiye, P.O., Jayawardane, A.K.W. and Harris, F.C. (1998) Construction Productivity Management, Longman, England.

PMI (1996) A Guide to the Project Management Body of Knowledge, Project Management Institute, PA, USA,

Sommerville, J. and Robertson, H.W. (2000) A scorecard approach to benchmarking for tota quality construction. International Journal of Quality and Reliability Management, 17(4/5), 453 $-466$.

(Footnotes)

1 These procedures and work instructions could be drawn from the company's quality management system or developed specifically for the project at hand.

${ }^{2}$ Enterprise Planning Associates, Project Management Maturity Model, Interactive Quick Look (1998).

${ }^{3}$ The present Conditions of Contract that stipulate the Contractor's responsibility to produce a quality product only insist on the aspects of 'Quality Control' (ICTAD, 1989; ICTAD, 2002). Some standard forms of contract such as those published by FIDIC require the contractors to institute a quality assurance system at project level to demonstrate compliance with requirements of the contract. The FIDIC Conditions of Contract (FIDIC, 1999) insists that the quality procedures and compliance documents be approved by the Engineer (Consultant) and gives authority to him for auditing any aspect of the quality system. 